\title{
Optimal Participation of Wind Power in the Liberalized Power Market
}

\author{
Ting Dai*. Wei Qiao** \\ *Department Electrical Engineering, University of Nebraska-Lincoln \\ Lincoln, NE 68588-0511 USA (e-mail:ting.dai@huskers.unl.edu) \\ **Department Electrical Engineering, University of Nebraska-Lincoln \\ Lincoln, NE 68588-0511 USA (Tel: +1-402-472-9619; e-mail:wqiao@engr.unl.edu)
}

\begin{abstract}
While installing wind power into the liberalized power market can reduce the operation and fuel costs of the power system, it also increases the imbalance cost and need for reserve. Due to this contradictory, there is a need for planning the amount of wind power in the power system. This paper proposes a model following American power market rules to find the optimal participation of wind power. This model assumes that wind power producer can bid into both day-ahead and real-time market and pay imbalance cost due to wind power prediction errors. A case study will be presented where the proposed model will be tested with simulation results on a practical power system.
\end{abstract}

Keywords: wind power, power market, reserve requirement, optimal participation

\section{INTRODUCTION}

Wind power is a clean, renewable, and intermittent energy source. Due to increasing concerns over environmental problems and climbing prices of natural gas and oil, in recent years, there has been a dramatic increase in the amount of wind power installed around the world. Many countries, e.g., Denmark, Germany, Spain, Ireland, Great British, China, India, and the United States, have plans to further increase the installed wind capacity (Tuohy et al., 2009). With the rapid increase in wind power capacity, it becomes increasingly important to find optimal strategies for wind power producers to sell their generation into the electricity market. Currently, most of the wind power in the United States is sold on long-term power purchasing agreements (PPAs). However, there is an interest in merchant wind generation, and some of the wind generation in the United States is already being sold directly into the day-ahead and real-time electricity markets (Botterud, et.al, 2010).

However, in the liberalized electricity markets, producers will have to propose bids in advance while the wind power prediction may not be accurate (Usaola and Angarita, 2007). In order to cope with the fluctuations and the partial unpredictability in the wind power production, other units in the power system have to be operated more flexibly to maintain the stability of the power system. Technically this means that a higher penetration of wind power will require a higher capacity of spinning and nonspinning reserves and an increasing use of these reserves. Consequently, the prices in ancillary service markets are expected to increase (Christoph, et.al, 2009). On the other hand, the fuel and operation costs of the whole system will decrease with the increase of wind penetration. Such a contradiction indicates that there exists an optimal wind penetration into a system in terms of the total profit of the system. For an Independent System Operator (ISO) market, this total profit translates to the social welfare that is realized through the market optimization.
This paper looks at how the total profit of a system changes with different percentages of wind penetration into the system, by gradually increasing the penetration percentage while maintaining the system reserve requirement dictated by the load shedding intolerance criteria. An optimization model is proposed to find the optimal wind penetration. For a given wind penetration percentage, the model optimizes the system reserve resources to achieve the maximum total profit of the system, which is equivalent to the social welfare corresponding to an ISO market. Then increase the wind penetration percentage by a step size and find the new maximum total profit of the system (the new social welfare of the market). This process continues until the optimal wind penetration is found, which corresponds to the maximum social welfare (or the maximum of the maximum total profit among all penetration percentages).

This paper is organized as follows: First, a brief overview of U.S. power market policies and the related market models are provided in Section 2. Section 3 discusses the relationship between the required reserve and wind penetration. Section 4 describes the proposed market model. Simulation results are provided in Section 5 to demonstrate the use of the model to find the optimal participation of wind power in a practical power system. The main findings of the paper are summarized in the last section.

\section{AMERICAN WIND POWER}

In the United States, approximately $70 \%$ of the installed wind power through 2008 was sold through PPAs, mainly to utilities (Bolinger and Wiser, 2009). Most of the wind power generation is therefore not being bid directly into the dayahead markets by the wind power producers, but is integrated into the utilities' scheduling plans along with loads and other generating resources. However, ISOs and Regional Transmission Organizations (RTOs) in the United States are currently working on improving the integration of wind 
power into their day-ahead and real-time markets. The California ISO (CAISO) is requiring wind power plants in the Participating Intermittent Resource Program (PIRP) to bid their hour-ahead market according to the CAISO's shortterm wind power forecast (Hawkins, et.al, 2007). The New York ISO (NYISO) recently introduced new rules (Gonzales, et.al, 2009) to incorporate wind power in its Security Constrained Economics Dispatch (SCED). With the new rules, wind power plants will be required to bid into the realtime market. PJM, a regional transmission organization that coordinates the movement of wholesale electricity in all or parts of 13 states and the District of Columbia, has also introduced a scheme for day-ahead and real-time dispatch of wind power plants based on their bids. Also considering the European power markets, such as Nord Pool, where wind power can be bid into both day-ahead and real-time markets, it can be concluded that it is a trend to involve more wind power into the liberalized power market.

In this paper, the market model analyzes the power markets based on an hourly description of generation, transmission, and demand with the combination of technical and economical aspects. This is done on the basis of maximizing the revenue of the whole system. In the proposed model, two electricity markets are included:

1. A day-ahead market for financially delivering the electricity. The due times for day-ahead market bids vary among markets, but are at least 12 hours before the start of the operating day. In the proposed model, it is assumed that the market is cleared at noon 12:00 for the following day.

2. A real-time market for handling deviations between the expected productions agreed upon the day-ahead market and the realized values of production in the actual operation hour. The deadline for submitting bids to the real-time market varies widely among different markets. It is assumed that the regulating power can be traded up to one hour before delivery.

\section{QUANTIFY RESERVE DEMAND IN SYSTEM}

As wind power penetration grows, there are concerns that the unforecasted wind variations may coincide with large generation trips, which will cause the loss of largest infeed more frequently. In order to quantify additional reserve due to the increasing penetration of wind power, the method presented by Doherty and O' Malley (2005) is used to determine the relationship between reserve requirement and wind penetration.

\subsection{System Reliability Criterion}

There are many different reliability criteria used in power system analysis. In this paper, the reliability criterion is defined as the number of LSI being tolerated per year, where a LSI is an incident when there is no enough reserve to meet a generation shortfall. The LSI is related to the loss of load expectation (LOLE) reliability criterion used in many electricity systems by multiplying the average time for which the load is shed.

\subsection{Wind Power and Load Forecast Errors}

The one-hour load forecast error can be modelled as a Gaussian stochastic variable with a mean of zero and standard deviation of $\sigma_{\text {load, } h}$. Wind power forecast errors generally increase as the forecast horizon increases. The onehour wind power forecast error can also be modeled as a Gaussian stochastic variable with a mean of zero and a standard deviation of $\sigma_{\text {wind,h }}$.

\subsection{Reserve Calculation}

The methodology used in (Doherty and O' Malle, 2005) related the reserve level on the system in each hour to the reliability of the system over the year. At any hour, the probability of load shedding, $P L S_{h}$, is the yearly reliability criterion LSI divided by the number of hours per year.

$$
P L S_{h}=\frac{L S I}{8760}
$$

The load shedding may happen in three different scenarios: 1) having an unforecasted wind and load variation greater than the system reserve level; 2) having a generation trip (full or partial) and an unforecasted wind and load variation greater than the system reserve level; and 3) having a generation trip and an unforecasted wind and load variation after a previous generation trip before any load shedding action is taken.

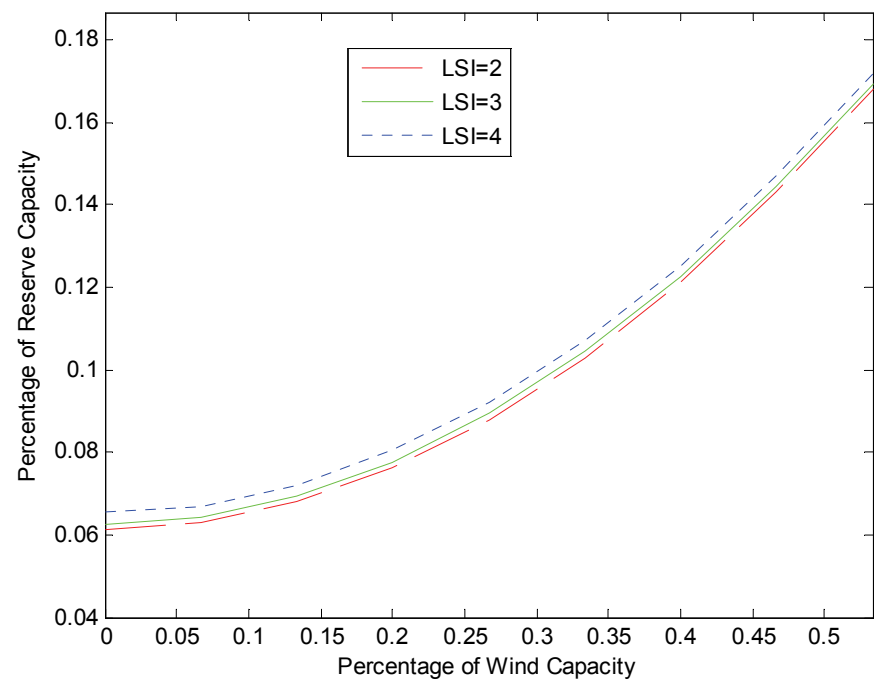

Fig.1. The required system reserve level against the level of wind power penetration for three different numbers of LSI per year and a wind power forecast horizon of 3 hours.

\subsection{Result}

The CASIO serves approximately 100 utility companies with a total installed generating capacity of 56,000 MW. The full outages of generation range from about 0.003 for the least reliable units to about 0.0006 for the most reliable units. The reserve requirement is solved by using MATLAB optimization toolbox. Fig. 1 shows the required reserve level for different number of LSI per year against increasing wind 
power penetration. As the wind power penetration increases the system reserve level must also increase or the whole system will suffer a decrease in reliability. It can be seen that $25 \%$ penetration of wind capacity results in roughly $40 \%$ increase in the need for reserve. This consequently will result in the cost of reserve to increase.

\section{MODEL DESCRIPTION}

The proposed model is defined as a single region model, where the trading power with other market is not considered. Additionally, it is assumed that the transmission capacity is sufficient in the system and transmission congestion will not happen

\subsection{Key Equations of the Model}

\section{A. Objective Function}

The objective of the model is to maximize the total profit of the whole power market. The profit is the total revenue of the system minus the fuel consumption cost and the start up cost and build up cost of reserves.

$$
\begin{aligned}
\operatorname{Max} V_{o b j} & =\sum_{t \in T} \sum_{i \in I} p^{L M P} * P_{i, t}-\sum_{t \in T} \sum_{i \in I} F_{i, t} * f_{i, t}^{\text {Price }} \\
& -\sum_{l \in R} \sum_{t \in T} c_{l, t}^{\text {startup }}-\sum_{l \in R} b_{l}^{\text {price }} * R_{l}
\end{aligned}
$$

where $p^{L M P}$ is the yearly average locational marginal price (LMP); $P_{i, t}$ is the power sold by unit $i$ at the day-ahead and real-time market at time $t ; F$ is the total fuel consumption; $f$ is the fuel price; $c_{l, t}$ is the start up cost of the reserve $l$ at the beginning of time $t$; and $b_{l}$ is the building price for reserve $l$.

\section{B. Balance of Demand and Supply in Day-Ahead and Real-} Time Markets

The day-ahead balancing is usually met by $12: 00 \mathrm{PM}$ on every day for the next 24 hours for most ISOs. The sum of power produced by generation including wind power is equal to the sum of demand that is required in day-ahead market.

$$
\sum_{i \in I^{\text {Dispatch }}} P_{i, t}^{\text {Day-Ahead }}+p_{t}^{\text {Bid-Wind }}=d_{t}^{\text {Bid }}
$$

where $P_{i, t}^{\text {Day-Ahead }}$ is the power bid into the day-ahead market by unit $i$ at time $t ; P_{t}^{\text {Bid-Wind }}$ is the wind power bid into the day-ahead market; and, $d_{t}^{\text {Bid }}$ is the bid demand at time $t$.

If the expected wind power production is higher than the actual wind power production, a demand for up reserve arises; conversely, a down reserve requirement arises. The real-time market deals with the deviation between production and consumption agreed upon day-ahead market. The total reserve required is equal to the sum of wind prediction error and load shedding.

$$
\begin{aligned}
\sum_{l \in I^{\text {Reserve }}}\left(R_{l, t}^{+}-R_{i, t}^{-}\right) & =p_{t}^{\text {Bid-Wind }}-p_{t}^{\text {Actual-wind }}+d_{t}^{\text {realized }} \\
& -d_{t}^{\text {Bid }}+d_{t}^{\text {shedding }}
\end{aligned}
$$

where $R_{l, t}{ }^{+}$and $R_{l, t}{ }^{-}$are the up and down reserve used in the real-time market at time $t$, respectively; $p_{t}^{\text {Actual-wind }}$ is the actual wind at time $t ; d_{t}^{\text {realized }}$ is the demand realized in the day-ahead market; and $d_{t}^{\text {shedding }}$ is the demand that is shed in the real-time market.

\section{Reserve Constraints}

As mentioned in Section 3, the maximum reserve is calculated and the total reserve used in the system cannot be larger than this value.

$$
\sum_{l \in I^{\text {Reserve }}}\left(R_{l, t}^{+}+R_{i, t}^{-}\right) \leq R_{\max }
$$

where $R_{\max }$ is the maximum reserve capacity in the system.

\section{Wind Capacity Constraints}

The wind capacity constraint is expressed as:

$$
0 \leq p^{\text {bid-wind }} \leq w^{*} P_{\text {total }}
$$

Where $w$ is the percentage of wind penetration; and $P_{\text {totoal }}$ is the total generating capacity of the power system.

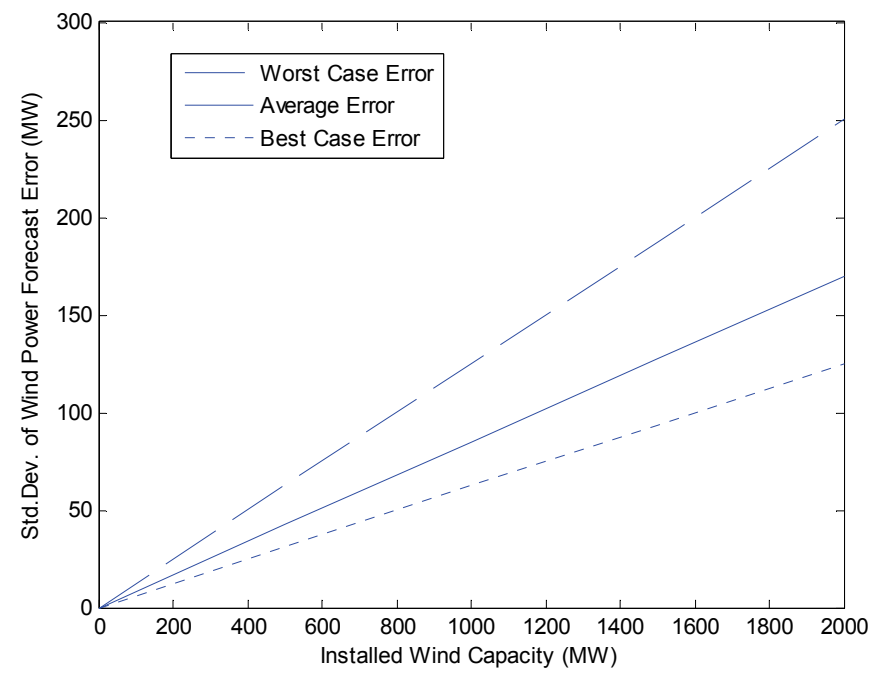

Fig.2. Standard deviation of average wind power forecast error along with the best- and worst-case scenarios versus installed wind capacity.

\subsection{Wind Forecast Error}

When the atmospheric situation is unstable, the numerical weather prediction and consequently the wind power forecasts will be poor. On the contrary, when the atmospheric situation is stable, one can expect more accurate wind power forecasts. The work of (Pinson and Kariniotakis, 2003) has developed a weather stability index called the "meteo-risk index" and has concluded that the relationship between this index and the magnitude of the forecast errors of individual wind farms is roughly linear. According to the frequency of occurrence of different weather situations as expressed by the 
meteo-risk index, the best and worst scenarios corresponding to the most and least accurate total wind power forecast error likely to be, respectively, have been established. Fig. 2 shows the standard deviations of the total wind power forecast errors for the best and worst scenarios and the average wind power forecast error versus the installed wind capacity.

\subsection{Reserve Requirement Optimization}

Based on wind forecast error, there are three scenarios: the best case, the worst case, and the average case. In each case, the reserve is optimally scheduled at the beginning of each hour.

\section{RESULT AND DISCUSSION}

The CAISO market is used as a case study to demonstrate the impact of wind penetration on the total profit of the market by using the proposed model. The CAISO is responsible for managing the flow of electricity and maintaining the reliable operation of the electricity transmission grid for the majority of the state of California. Currently, it has a total generating capacity of $56,000 \mathrm{MW}$. The renewable energy penetration must reach $20 \%$ by 2017 .

The daily LMP usually varies significantly during the year. Fig. 3 illustrates the daily average LMP of the CAISO during December, 2009 (California ISO, 2010). In this paper, yearly average LMP is used. The average LMP of 2009 for the CAISO is $\$ 34.5$ (Federal Energy Regulatory Commission, 2010).

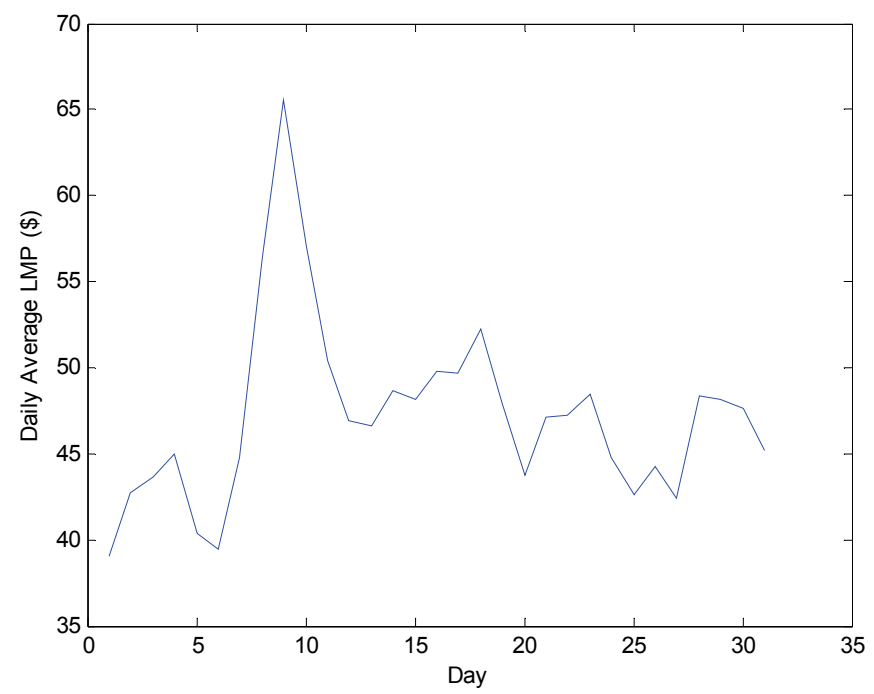

Fig.3. The CAISO's daily average LMP in December, 2009.

Table 1 shows the start-up cost, variable cost, and other operation cost of different power plants used for case studies in this section.

The proposed model is applied to find the optimal wind power penetration for the CAISO with the information from the public source (California ISO, 2010) and reasonable assumptions made by the authors for this study. Those assumptions include the following: 1) yearly average LMP will be used in the model; 2) the trading with other power markets is not considered; and 3) transmission capacity limits is not considered. The results are shown in Figs. 4-7 for illustration purposes.

Table 1. Costs of different fuel type (Swider, 2007)

\begin{tabular}{|c|c|c|c|c|}
\hline Type & Coal & Lignite & Gas & Nuclear \\
\hline Start-up cost (\$/MWh) & 6.9 & 6.9 & 11.1 & 2.8 \\
\hline $\begin{array}{c}\text { Other variable cost } \\
(\$ / M W h)\end{array}$ & 2.7 & 2.2 & 1.5 & 0.69 \\
\hline $\begin{array}{c}\text { Fixed operation cost } \\
(\$ / M W h)\end{array}$ & 59 & 72.7 & 26.4 & 52.9 \\
\hline
\end{tabular}

As shown in Fig. 4, at low levels of wind penetration, the total market profit increases with the increase of wind penetration. The maximum profit is obtained at a wind penetration of $25 \%$, which is defined as the optimal wind penetration. Beyond this level of penetration, the total market profit decreases with the increase of wind penetration.

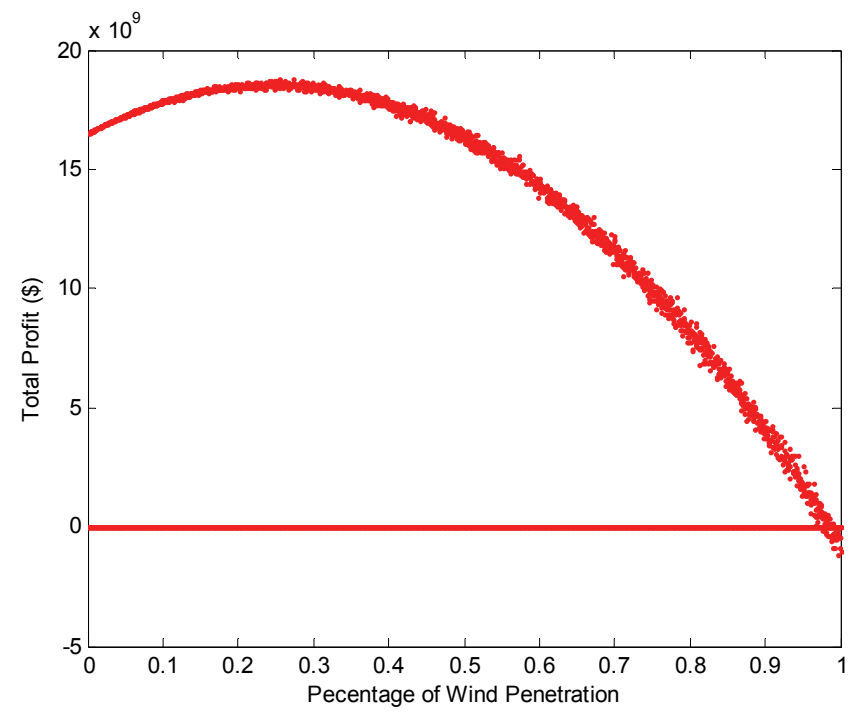

Fig.4. The relationship between wind penetration and total profit of the CAISO: base case.

\subsection{The Impact of the Average LMP}

As the wind penetration increases, the LMP tends to decrease. As a result, the operation cost of the whole system will decrease (Osborn, 2009). Based on the work of (Osborn, 2009), the relationship between the average LMP and wind power penetration was studied and the result is shown in Fig. 5. It shows that the LMP decreases with the increase of wind penetration. For example, the LMP decreases by $2.2 \%$ at $20 \%$ wind penetration and by $4.1 \%$ at $25 \%$ wind penetration. 
By taking into account the variations of the LMP at different levels of wind penetration, the optimal wind penetration point moves to $16 \%$, as shown in Fig. 6 . The increase in the wind penetration results in the decrease of the average LMP, which in turn changes the optimal wind penetration to a lower level.

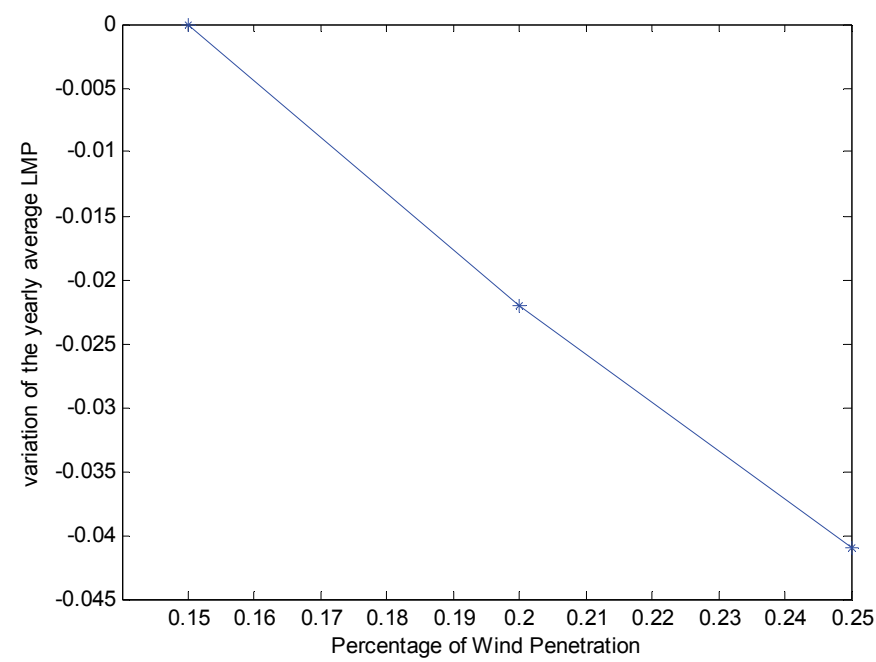

Fig. 5. The variations of the LMP at different levels of wind penetration.

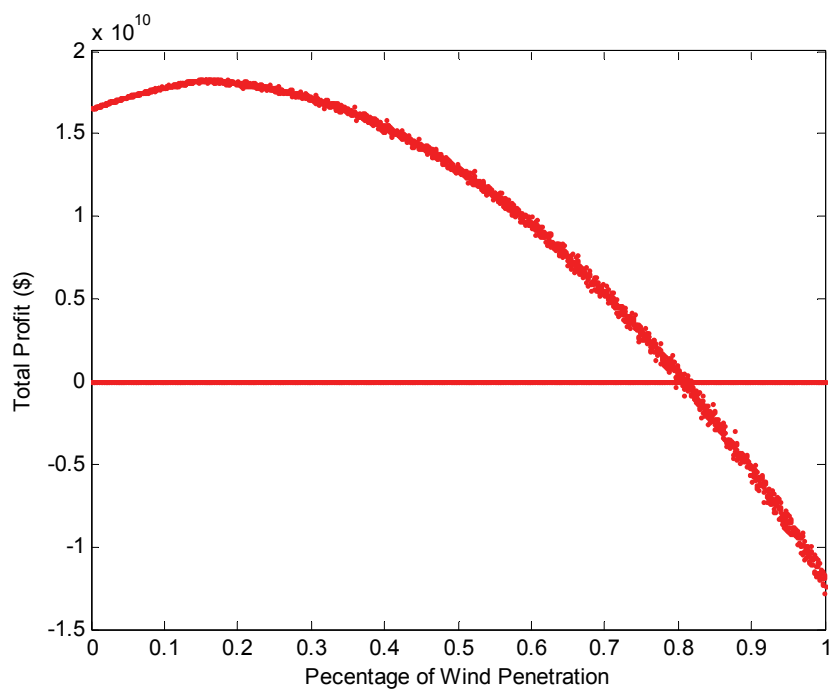

Fig.6. The relationship between wind penetration and total profit of the CASIO: considering the impact of the LMP.

\subsection{The Impact of Energy Storage}

The use of energy storage integrated with wind power is commonly considered in a system for increased flexibility. If wind plants can operate along with energy storage, the total amount of reserve can decrease. The following table shows the costs for two commonly used energy storage technologies. Compared to pumped hydro, compressed air energy storage (CAES) has a lower cost for storing electrical energy. If $20 \%$ of the reserve is replaced by CAES, the result is shown in Fig. 6.

The use of CAES will lower the operation cost of the system and thus increase the optimal wind penetration level to $18 \%$. The research of combining CAES with wind is starting to grow (Swider, 2007). This energy storage technology may provide a way for accommodating more wind penetration in the system.

Table.2. Costs of two different types of energy storage

\begin{tabular}{|c|c|c|}
\hline Type & Pumped hydro & CAES \\
\hline Start-up cost $(\$ / \mathrm{MW})$ & 10.1 & 5.5 \\
\hline Other variable cost $(\$ / \mathrm{MWh})$ & 3.4 & 1.6 \\
\hline Fixed operation cost $(\$ / \mathrm{MW})$ & 34.7 & 30.6 \\
\hline
\end{tabular}

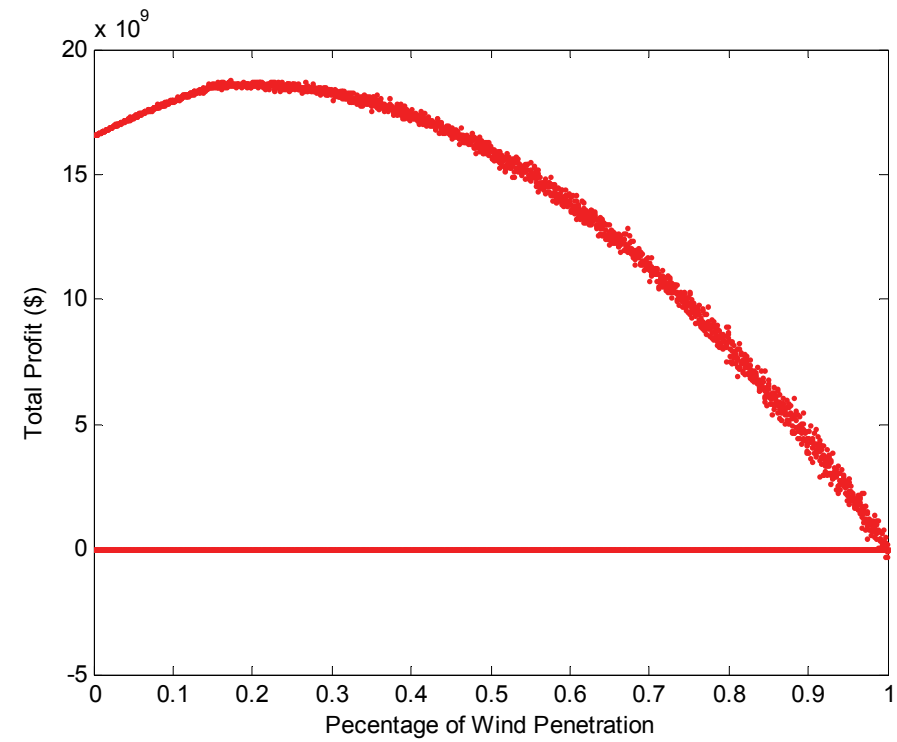

Fig.7. The relationship between wind penetration and total profit: considering the impact of CAES.

\section{CONCLUSION AND FUTURE WORK}

Wind Power has a great potential to participate in the current power market. However, due to the inherent uncertainties in wind power forecasts, the increase of wind penetration will lead to the increase in reserve cost. In this paper, a model has been presented to solve such contradictory. The maximum reserve has been fixed at different levels of wind power penetration; the hourly used reserve has been optimized based on three wind forecast scenarios. Simulation results have been shown through a simplified case study of wind participation into the CAISO. It has been assumed that CAISO is a single region market with unlimited transmission capacity. The total profit of the market has been calculated for different levels of wind penetration and the optimal wind penetration level has been calculated. Moreover, the 
influence of the LMP and energy storage involvement on the total market profit has been studied. According to the case study, the whole power market can benefit from wind power penetration at certain levels. However, once penetration level exceeds the optimal value, the total profit of the system may start to decrease if there is no energy storage to replace additional reserve required associated with the increasing wind. This paper has provided a method to assess the optimal wind penetration in the market.

In future work, hourly LMP will be introduced into the model to provide more accurate results. Additionally, the trading with other power markets and transmission capacity limits will also be considered.

\section{ACKNOWLEDGMENTS}

The authors gratefully acknowledge financial support for this work from the National Science Foundation under CAREER Award ECCS-0954938. Any opinions, findings, and conclusions or recommendations expressed in this paper are those of the authors and do not necessarily reflect the view of the National Science Foundation.

\section{REFERENCES}

Bolinger, M. \& Wiser, R. (2009), "2008 Wind technologies market report," Lawrence Berkeley National Laboratory.

Botterud, A., Wang, J., Bessa, R. J., and Miranda, V., (2010), "Risk management and optimal bidding for a wind power producer," In Proceedings of the IEEE PES General Meeting 2010, Minneapolis, Minnesota, USA.

California ISO (2010). [Online]. Available at: http://www.caiso.com/23c0/23c09b481a480.html

Christoph, W., Peter, M., Rüdiger, B., and Herike, B., (2009), "WILMAR: A stochastic programming tool to analyze the integration of wind energy." Optimization in the Energy Industry, 432-458.

Doherty, R. and O' Malley, M. (2005), A new approach to quantify reserve demand in systems with significant installed wind capacity," IEEE Trans. Power Systems, $8(2), 587-595$.

Federal Energy Regulatory Commission. [Online]. Available at: electric/california.asp

http://www.ferc.gov/market-oversight/mkt-

Gonzales, R., Mukerji, R., Swider, M., Allen, D., Pike, R., Edelson, D., Nelson, F., Adams, J.J., (2009), "Integration of Wind into System Dispatch." New York ISO White Paper.

Hawkins, D.L., Blatchford, J., and Makarov, Y.V., (2007) "Wind integration issues and solutions in California," In Proceeding of the IEEE PES General Meeting, Tampa, FL

Osborn, L. (2006), "Impact of Wind on LMP Market," IEEE PSCE, 216-218.

Pinson, P., and Kariniotakis, G.N. (2003), "Wind power forecasting using fuzzy neural networks enhanced with on-line prediction risk assessment," In Proceeding of the IEEE Bologna Power Tech Conf.
Swider, J. (2007), "Compressed Air Energy Storage in an Electricity System with Significant Wind Power Generation", IEEE Trans. Power Systems, 22(1), 95-102.

Usaola, J. and Angarita, J. (2007). Bidding wind under uncertainty. In Proceeding of the International Conference on Clean Electrical Power, 754-759. 